Kansas State University Libraries

New Prairie Press

Academic Chairpersons Conference

36th Academic Chairpersons Conference

Proceedings

Houston, TX

\title{
Talking to a DIsgruntled Faculty Member
}

John R. Hamilton Jr

Park University, john.hamilton@park.edu

Follow this and additional works at: https://newprairiepress.org/accp

Part of the Educational Leadership Commons, Higher Education Administration Commons, and the Organizational Communication Commons

(c) (1) (2)

This work is licensed under a Creative Commons Attribution-Share Alike 4.0 License.

\section{Recommended Citation}

Hamilton, John R. Jr (2019). "Talking to a DIsgruntled Faculty Member," Academic Chairpersons

Conference Proceedings. https://newprairiepress.org/accp/2019/department/1

This Event is brought to you for free and open access by the Conferences at New Prairie Press. It has been accepted for inclusion in Academic Chairpersons Conference Proceedings by an authorized administrator of New Prairie Press. For more information, please contact cads@k-state.edu. 


\section{TALKING WITH A DISGRUNTLED FACULTY MEMBER}

John Hamilton

Park University 


\section{Objectives}

- Share experience of Park University in helping members navigate conflict situations more successfully

- Examine various techniques for addressing interpersonal conflict

- Learn the value of active listening

- Understand how to constructively probe for additional information from a disgruntled person

- Discuss options and benefits of creating your own training 


\section{Park University}

- Issue

- Faculty and staff appeared to be having difficulty expressing thoughts and concerns in a manner that was not offensive to others and/or perceived as unsafe for their future relationships (Conflict situations)

- Actions to address the issue

- Small internal grant to send one person to Crucial Conversations training and trainer certification course

- Crucial Conversations training provided for 42 faculty members and 15 staff members

- Goal

- Help faculty and staff members better communicate in conflict situations 


\section{Park University}

\section{- Results}

- Surveys at beginning and end of the two-day training sessions and a survey 90 days after training completed

- Currently analyzing the statistical data gathered

- Comments from participants were positive overall

- $63 \%$ response rate on survey \#3 (90 days after training) 


\section{Park University}

- The benefit of this training was that I'm more aware of the right ways to handle a conflict, even though I may not be able to carry them out properly. I need more practice.

- What I appreciated from the course is that many people participated in the training and if there is a conflict we have a common reference

- This training helps me transfer from the averted situation that I get stuck to master my stories. Eventually, I can move from a silence or violence stage to a safety and a pool of shared meaning stage. Great workshop!

- I can't remember all of the names of the techniques but recall trying to listen, recall/restate, and ask questions in order to move toward understanding or a solution.

- The one techniques I constantly use is the one where one factually states what has been observed and then state "which leads me to believe" allowing the other person to correct the "belief" or not.

- Learning methods to keep emotion separate from fact. ${ }^{*}$ Keeping my motive and that of the other person in mind. ${ }^{*}$ Listening skills!

- *intent is key *A person can become/move to violence when they feel unsafe. * watch to notice others feeling unsafe

- *You have to look at yourself first. *think before you act. ${ }^{*} d o n ' t$ assume.

- Many comments indicated that the person was now thinking about how to handle conflict situations instead of just reacting to them.

- Respondents also indicated that they appreciated learning a skill to use in conflict situations 


\section{Park University}

- In comparing the qualitative comments between the immediate post survey and the final survey, a couple of things I found interesting:

- - The faculty leaders in particular seemed to hone in on the role/importance of facts in the conflict resolution process. Several cited the "facts should precede feelings" element of the training.

- $\quad$ Other notes from faculty leaders in particular that I found interesting:

- o Faculty leaders reported increased awareness of their own conflict reactions.

- $\quad$ Faculty leaders reported increased awareness of the need to keep emotion separate from fact; discern single incidents from patterns; use mirroring and paraphrase to clarify issues; and, in general, have an awareness earlier on of when a conversation is "critical" for one of their faculty colleagues. I found these findings encouraging. As you know, faculty leaders (Chairs, etc.) often don't see their identity as being a manager, or at least don't see their primary identities as being managers/supervisors, so the fact that the training has made them more attuned to the needs of their faculty is encouraging.

- o At least one faculty member noted applying the training to her teaching.

- - Observations from the final survey:

- o The final survey responses didn't identify particular strategies as much (i.e., STATE), but definitely emphasized: using empathy, "starting with the heart," honestly conveying their own viewpoint, active listening.

- o "I am listening more. I state empathy more. I ask more clarifying questions. This is going to take time and practice to fully integrate and move from a stimulus-response stance."

- o "I take a minute before I start assuming why people did/do things. It has helped me reduce gossip participation by thinking about the harm it does and the assumptions it makes."

- o "Many times - I mostly rely on the technique of using facts to begin the conversation. I also attempt to use good listening skills to find out what the real motive is behind the conflict/behavior." 


\section{Introduction}

- Supervising faculty members who are disgruntled can be frustrating

- Having some skills in conflict resolution can be helpful in diffusing feelings of frustration and anger

- Addressing conflict is not easy or quick, but if done well it is usually successful

- It can also be a positive experience if approached correctly

- We must learn to "do what come unnaturally" (Hocker and Wilmot) 


\section{What is a "disgruntled" faculty member?}

- A dictionary definition says "angry or dissatisfied"

- Some synonyms are:

- Discontented

- Aggrieved

- Resentful

- Fed up

- Unhappy

- Disappointed

- Griping

- So, for our purposes, this is a faculty member who is upset and may choose to react to their upset in an emotional, irrational, or unacceptable manner 


\section{Conflict}

- Disagreement between two or more persons

- The disagreement can involve not only interpersonal disagreements but also policy decisions

- May involve perceived mistreatment

- In some cases it can involve a perceived affront to a person's values or dignity

- In any of the above situations it is important to try to accurately understand what is upsetting the person

- Conflict resolution skills can guide you through that process while minimizing the possibility of additional damage being done 


\section{Why do I have have to change?}

- The four major groups that write about conflict emphasize that the only person you can change is you

- The tone you set can diffuse a situation and calm the emotions of the upset faculty member

- Being able to reman calm and in a problem solving mode will help you be more effective in diagnosing the problem and creating problem solving actions 


\section{Techniques to Address Conflict}

- Know what you want out of the interaction

- Is it more important to solve the problem or maintain a relationship

- In some cases a problem needs to be solved but there is no reason to preserve a relationship - e.g., property ownership or dispute about a service provided

- Be careful not to damage the relationship but focus more on solving the problem

- In other cases it is important to preserve a relationship while solving the problem at hand - e.g., neighborhood dispute, performance of subordinates 


\section{Techniques to Address Conflict Situations}

- Separate the person from the problem

- Often we tie our feelings toward the person with the issue at hand

- Clouds our ability to understand the elements of the problem

- Focus on what is being said and ask probing questions to obtain more specific information about the problem

- Look for common purpose to encourage problem solving

- Work to protect the dignity of the other person during the conversation 


\section{Dignity}

- The Ten Essential Elements of Dignity

- Acceptance of Identity

- Inclusion

- Safety

- Acknowledgment

- Recognition

- Fairness

- Benefit of the Doubt

- Understanding

- Independence

- Accountability 


\section{Techniques to Address Conflict Situations}

\section{- Listen actively}

- This can be difficult but it can be learned

- Often difficult because of tying the person with the problem, so this is a good technique to use to separate the person from the problem

- When people are upset and are telling you what they are mad about we often spend time trying to craft our response to them

- Often this response is our defense of ourselves or our actions and often our response just fuels the problem and escalates the conflict

- Try this instead, when someone becomes agitated, after they finish their statement respond with, "This issue really seems to bother you. Tell me more about why it is so upsetting."

- Paraphrase back to make sure you understood what the other person said.

- Listen to what is really being said 


\section{Techniques to Address Conflict}

- Move from "either/or" to "both/and"

-What often stifles good problem solving is the sense that there is only one "right" answer or solution

- Summarize what the other person wants and what you want with "How can we do (what the other person desires) and do (what I desire)?

- This opens a platform for discussion and problem solving.

- May create an entirely different outcome after discussion 


\section{STATE My Path (from Crucial \\ Conversations)}

- S - Share your facts

- T - Tell your story

- A- Ask for others' paths

- T - Talk tentatively

- E - Encourage testing 


\section{Techniques to Address Conflict Situations}

- So what is the most important action?

- Difficult to answer, but multiple conflict resolution experts tend to agree on one

$$
\text { Empathy }
$$

(don't confuse with sympathy!) 


\section{Sharing conflict resolution skills with faculty members}

- It can be valuable to teach faculty members conflict resolution skills

- Even the use of one or two techniques can be beneficial

- If they know techniques to use in conflict situations they may be less likelihood that that Chairpersons or Deans would need to intervene or diffuse situations

- There are professionally prepared programs such as Crucial Conversations, or you can create your own training utilizing many of the resources included at the end of this presentation 


\section{Sharing conflict resolution skills with faculty members}

- Using one or two of the listed resources could be a good start

- Identify the problem you need to address, or if that is difficult to specifically identify, create a general training that highlights 3-5 techniques to use in addressing conflict

- Determine time available and means to be used to deliver training.

- Could be short multiple sessions or one to two larger sessions

- Use a survey tool to obtain feedback to see if goals are being met and if adjustments to the training are needed

- Start small if necessary, but just start! 


\section{Suggested Resources}

- Hicks, D. (2011). Dignity: Its essential role in resolving conflict. New Haven, CT: Yale University Press.

- Hocker, J.L. \& Wilmot, W.W. (2014). Interpersonal Conflict, $9^{\text {th }}$ ed., New York, NY: McGraw-Hill.

- Patterson, K., Grenny, J., McMillan, R., and Switzler, A.

(2011). Crucial conversations: Tools for talking when stakes are high, $2^{\text {nd }}$ ed., New York, NY: McGraw-Hill.

- Patterson, K., Grenny, J., McMillan, R., \& Switzler, A. \& Maxfield, D. (2013). Crucial accountability: Tools for resolving violated expectations, broken commitments, and bad behavior, $2^{\text {nd }}$ ed., New York, NY: McGraw-Hill. 


\section{Suggested Resources}

- Porath, C. (2016). Mastering civility: A manifesto for the workplace. New York, NY: Grand Central Publishing

- Stone, D., and Heen, S. (2014). Thanks for the feedback: The science and art of receiving feedback well. New York, NY: Penguin Books

- Stone, D., Patton, B., and Heen, S. (2010). Difficult conversations: How to discuss what matters most. New York, NY: Penguin Books 


\section{Contact Information}

John Hamilton

Associate Professor and Chairperson of Criminal Justice

Park University

8700 N.W. River Park Dr.

Parkville, MO 64152

john.hamilton@park.edu 